\title{
Development and Validation of the Perceived Psychological Capacity Scale as a Consideration for Determining Employee Productive Age Period
}

\author{
Marina Sulastiana, Dhevy Puswiartika, Rezki Ashriyana Sulistiobudi, Ernie Tisnawati Sule
}

\begin{abstract}
Purpose of Study : The changes over the age period especially in employee occur physically and psychologically. The employee psychological condition changes can be affecting the work activities, productivity and performance. Although WHO and another national regulation has been settled the retirement age limit for employee, but there always some psychological down turning happen. While, there has been little empirical research conducted in relation to diagnostic tool for perceived employee productive age period. This study aims to introduce and explore the factor structure of a new measure of Perceived Psychological Capacity Scale.

Methodology : To validate this scale we used Exploratory Factor Analysis, Confirmatory Factor Analysis and Bivariate Correlation with Other Correlated Variable (Human Capital). The participants in this study were 267 employees in a company which provide railways transportation services in Indonesia, with an age range of 39-56 years old.

Result : The analysis suggest that Perceived Psychological Capacity Scale is valid and reliable. It contains 25 items in 4 dimensions i.e. Cognitive, Motivation, Emotion, Social Interaction. This result indicates that Perceived Psychological Capacity Scale can measure the decrease of psychological capacity based on employees' perceived perception particularly in service work scope on certain age.

Implications/Applications : This study can be used as an alternative tool to diagnose the productive age of employee based on their perceived psychological capacity specifically in railways transportation service employees. We cannot generalize the findings of this study for every employee in other jobs and company due to the limitation of this study.
\end{abstract}

Keywords: Productive Age Period; Psychological Capacity Scale.

\section{INTRODUCTION}

In order to achieve the company performance goal, work capacity and participation of senior employee in the company workforce still an issue. Work quality and work environment needed to be considered in the context of

Revised Manuscript Received on September 22, 2019.

Marina Sulastiana, Faculty of Psychology, Universitas Padjadjaran, Jatinangor, West Java. marina.sulastiana@unpad.ac.id

Dhevy Puswiartika, Faculty of Psychology, Universitas Padjadjaran, Jatinangor, West Java

Rezki Ashriyana Sulistiobudi, Faculty of Psychology, Universitas Padjadjaran, Jatinangor, West Java

Ernie Tisnawati Sule, BUMN Centre of Excellence, Universitas Padjadjaran, Jatinangor, West Java significant senior employees' contribution to keep the employee stay in their workplace or organization ${ }^{(1)}$. Moreover, effort to decrease work accidents and mental and physical stress also should be taken in consideration, which can increase employees' health condition that can be very beneficial for senior employees' wellness ${ }^{(2)}$. As advance technology assistance equipment influences healthier ways and lifestyle, nowadays individuals in the age of fifties look more active and productive than individual in the age of forties on earlier generation. A lot of sayings is "60 is the new 40 "(3).

Determination of retirement age in psychological perspective refer to Cherington ${ }^{(3)}$ who suggested that in the work lifespan, individual follows career stages which started from career determination, career stabilization, career maintenance, and regression.

In Indonesia labor regulation generally mention that employees are entering retirement period preparation on the age of 55 , to then retire in the age of 56 or 58 . In several higher education institutions, age of retirement is 65 years old for lecturer. In 2017 World Health Organization (WHO) has classified youth in 19-65 years old. These illustrations needed to be a reference to determine retirement age limit in a company. Earlier classification is based on ${ }^{(4)}$ when individual as employee can be classified to emerging adulthood, early adult, middle adulthood, and late adulthood (50-60 years old).

There is psychological condition from employee that still can be adjusted with work environment factors support but a few conditions are hard. According to ${ }^{(3)}$ individual who have better psychological adjustment approaching retirement is an individual who have sufficient cognitive ability on his age, emotional stability and wisdom, high work motivation, wide social interaction with family and co-workers.

Assessment of psychological aspects relevant to productive age limit in general is needed by the company (in this case, ground transportation service company) in consideration of human resource management in general and specifically in setting age retirement limit. Currently, productive lifespan reference are based on common age developmental stage, there are no clear reference to measure psychological capacity 
according employee's perception particularly in middle adulthood level (10-15 years to retirement).

Based on the last decade development, employees are seen and measured as Human Capital. In order to develop and validate employee's perception measurement regarding their psychological capacities especially in productive lifespan, as a consideration apparently it needed to be associated with Human Capital component which in content is employee's capital that can increase work productivity.

This research's purpose is to develop and validate the aspects of psychological capacities (cognitive, motivation, emotion and social interaction) related with productive lifespan at work and at the same time obtaining illustration of productivity downturn in late work lifespan. The result of this study is expected to be a consideration in determining retirement age limit and furthermore provide input for a more effective and efficient management levels and utilization of human resources, including career path, from recruitment and selections new employees and especially in relocation and empowerment, work termination or early retirement, as well as human resources performance improvement program.

\section{Literature ReVIEW}

\section{A. Psychological Dimension}

The psychological dimension consists of 3 dimensions or mental symptoms :cognitive, affective, and psychomotor ${ }^{(5)}$. The cognitive dimension is related to mental processes that reflect thinking, knowledge or the ability to acquire knowledge. Cognitive dimensions include attention, observation, response, imagination, memory, mind, and intuition. The development of cognitive abilities in middle adulthood has reached its peak ${ }^{(3)}$.

While the affective dimension is related to the assessment of pleasure or displeasure with something in a certain context and is subjective. Affective dimensions include feelings and emotions ${ }^{(6)}$. Specifically, empirical studies on employees in China showed that emotions associated with feelings of jealousy, joy, and fear experienced in the workplace can affect employee work performance ${ }^{(7)}$. Affective dimensions in middle adulthood are characterized by emotional stress. According to Erik Erikson in the theory of psychosocial development that was initiated, in this period individuals can have one of two sides of capacity possessed by individuals in middle adulthood, where one side is capacity wisdom and on the other hand is personal absorption capacity $^{(8)}$. Furthermore, psychomotor dimensions are related to psychological activities that contain active effort and are related to the implementation of a goal. Psychomotor dimensions include impulses, desires, and tendencies possessed by individuals. As for the psychomotor dimensions in middle adulthood, it is known that the psychomotor dimension is related to psychological activity that contains active effort and is related to the implementation of a goal ${ }^{(3)}$.

\section{B. Determination of Retirement Age Limits in a Psychological Perspective}

Determination of retirement age in a review of psychological perspectives related to the stages of individual career development, starting from career determination, career strengthening, career care, to the stage of career declined. The stage of setback is the last stage in a career where individuals face the end of their work and enter retirement $^{(3)}$. Individuals in the retirement age category basically can still be productive enough because they cannot be categorized as elderly. For most individuals, the middle adulthood is marked by the progress of work, marriage, increasing economy, becoming more active in participating in social activities, reducing activities that are mostly carried out physically and decreasing physical conditions, such as being tired and sick ${ }^{(3)}$.

In dealing with various changes related to retirement as described above, there are psychological conditions of good employees who can still be adapted to the support of work environment factors, as well as conditions that have been difficult to adjust again to the demands of work or activity ${ }^{(4)}$. The psychological condition of employees as individuals in the middle age range can affect employee work behavior. This assumption is supported by the opinion of Lewin ${ }^{(9)}$ who argues that behavior is the result of interaction between psychological functions originating from within the individual, including cognitive, motivational, emotional, and social interactions, as well as factors which come from outside the individual, namely: experience, training, challenges, and problems.

\section{Human Capital}

Human capital is an individual asset as an employee that contains knowledge, experience, skills, attitudes, values, and other personal attributes that have added value to the organization $^{(10)}$. Human Capital consists of Psychological Capital, Intellectual Capital, Emotional Capital, and Social Capital, or known as PIES human capital. Psychological Capital is the capital from psychological aspects that can contribute to the success of individuals as employees in the company, including self-efficacy, hope, optimism, and resilience. The results of the study proved that psychological capital was a potential mediator in the relationship between mindfulness and work engagement and well-being ${ }^{(11)}$. Intellectual Capital is the capital for organizations that consists of commitment to the organization and competence of employees in carrying out their work. Intellectual capital includes experience, skills, knowledge, and capabilities. Emotional Capital is the maturity capital that can contribute to the success of individuals as employees in the company. Emotional Capital consists of self-awareness, self-regulation, social skills, and social awareness. Social Capital is the capital that can contribute to the success of individuals as employees in the company. Social capital consists of network, trust, and civic norms. 


\section{METHODOLOGY/MATERIALS}

\section{A. Sample}

The samples used in our studies were from one of the transportation business stated owned company in Indonesia. This company was chosen because of the problem has been arising from its company. The ages are middle adulthood where this period begins to occur declines in physical capacity and another in psychological aspect ${ }^{(12)}$. There are 267 participants took part in this study.

\section{B. Procedure}

\section{1) Study 1: Pilot Study for Item Pool}

\section{a) Procedure (Study 1)}

We first used a panel of experts (psychological developmental researchers and employee productive behavior researchers) to given descriptions of each dimension and asked to rate each item on a 5-point Likert scale ( $1=$ does not capture the essence of the concept well, 5 $=$ captures the essence of the concept well). Items rated 4 and 5 on the Likert scale were retained.

\section{b) Result (Study 1)}

First, we wrote 40 items for this scale. Each psychological aspect has 10 items. Each item is adjusted to the specific area of this research, which is projecting how the employee perceptions related to the decreasing of psychological aspects on him i.e cognitive ability, motivation, emotion, and social interaction. After we conducted the discussion with a panel of experts, we eliminated 6 items that rated below 4 , indicated that the item doest not capture the essence of the concept. We get 34 items which has valid content as stated by the expert.

\section{2) Study 2: Validation of the Perceived Psychological Capacity Scale}

\section{a) Procedure (Study 2)}

All the participants answered the questionnaires using paper and pencil method. We received 267 completed responses out of 303 participants, achieving response rate of approximately $88,1 \%$.

\section{b) Measure (Study 2)}

All measures attempt to deal with common method variance, making it possible to test the discriminant validity of all included study variables. Perceived Psychological Capacity Scale and Human Capital items were scored on a 5-point Likert scale ranging from $1=$ strongly disagree to $5=$ strongly agree and were measured by 34 items for this study. We also calculated the differences perception of employee regarding declining of their psychological aspects from group of ages. Human Capital were measured by PIES (Psychological Capital, Intelectual Capital, Emotional Capital and Social Capital).

\section{c) Data Analysis}

We conducted 5 step analysis to validate the Psychological Capacity Scale : Exploratory Factor Analysis (EFA); Means, standard deviations, reliability; Validity by Relation to Other Variables ${ }^{(13)}$; One Way Annova Test to determine capacity variation in various group age; and CFAs were conducted by using the software AMOS 18.0 program with maximum likelihood estimation. Model fit was also determined by the root mean square error of approximation (RMSEA). Values of .08 or less indicate a reasonably fitting model relative to the model's degrees of freedom ${ }^{(14)}$. Additionally, the CFI, the non-normed fit index (NNFI), and the standardized root-mean-square residual (SRMR) were included ${ }^{(15)}$. CFI values greater than .95 are indicative of a well-fitting model, for SRMR a value close to .08 is considered good, while NNFI values close to 1.00 indicate a good $\mathrm{fit}^{(16)}$.

\section{d) $\quad$ Result (Study 2)}

\section{(1) Exploratory Factor Analysis}

The value of KMO/Kaiser-Mayer-Olkin ${ }^{(17)}$ shows the adequacy of the sample. Generally the KMO value is above 0.5 after testing a sufficient sample. Barlett's test of sphericity shows a correlation between variables, if it is significant ( sig <0.05) then factor analysis can be done. From the output above, the analysis results show the value of KMO 0.828 and barlett's test of significant sphericity. Therefore factor analysis can be continued.

The EFA indicated a clear four-factor structure. There were no cross-loadings, and all the factor loadings were above the stringent criteria of .35 (factor loading). The EFA indicated support for discriminant validity. Four factors emerged with eigenvalues greater than 1, accounting for $61.03 \%$ of the variance. Each item loaded on its appropriate factor. We derived 25 items from EFA. It consist of 7 items for cognitive function, 5 items for motivation, 7 items for emotion and 6 items for social interaction.

\section{(2) Descriptive Statistic, Age Differencess, and Relation to Other Variables}

Reliability (alpha) coefficient of Perceived Psychological Capacity Scale were ,846 and Alpha Coefficent for Human Capital were ,874. Table 1 stated that age correlated significantly negative with cognitive aspect only. Three aspects of Psychological Capacity Scale correlated significantly with the dimension of Human Capital. Only the perceived cognitive aspects that not show correlation with intellectual capital. It was implied that our Perceived Psychological Capacity Scale have the good criterion validity. 
Table 1. Descriptive and Bivariate Correlation

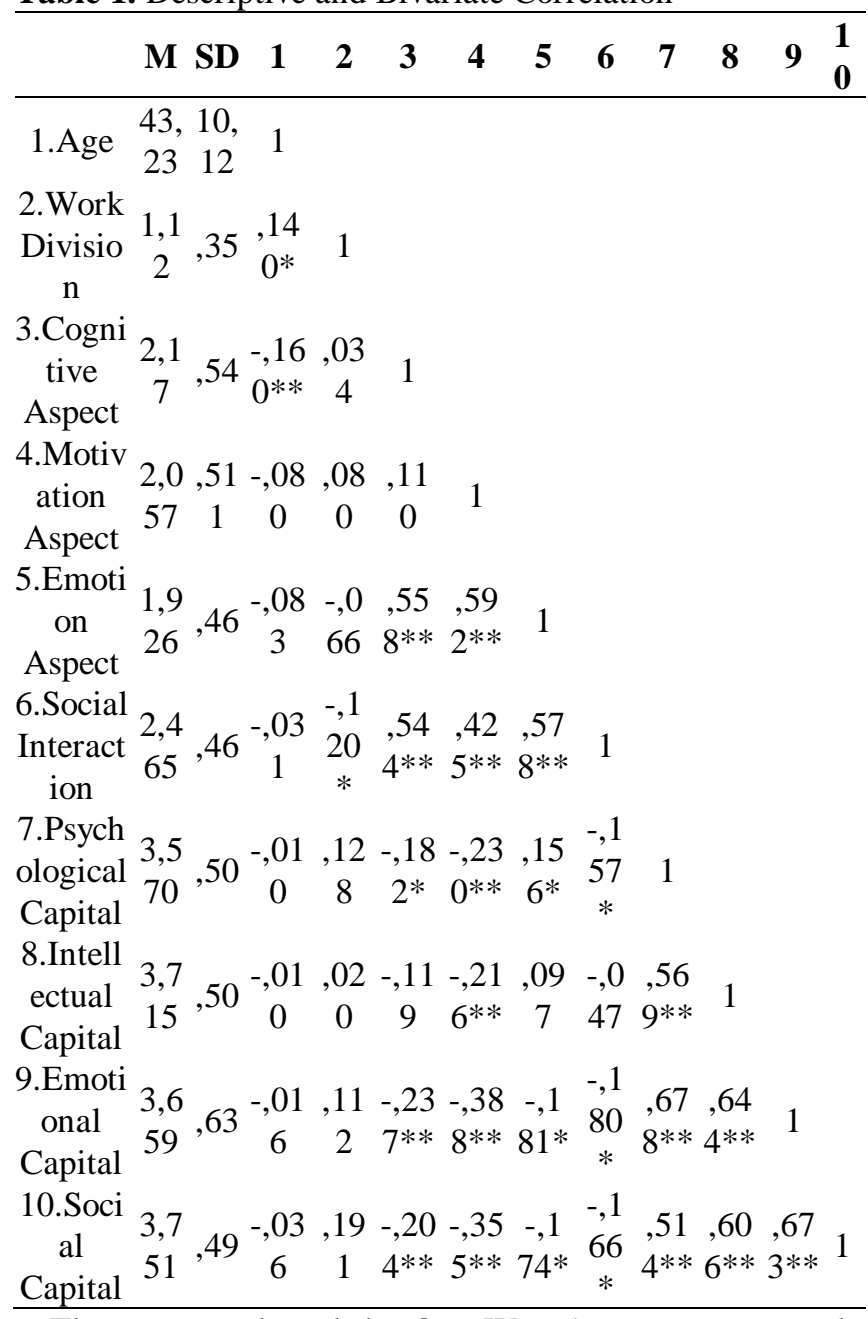

Then, we conducted the One Way Annova to test each aspects in differences group of age. The result stated that onlye cogntive aspects that vary by age. As the employee becoming older, they will feel decline more on cognitive ability.

Table 2. Differences by Age (One Way Annova Test Result)

\begin{tabular}{ccc}
\hline Aspects & F & Sign \\
\hline Cognitive & 2,205 &, $088^{*}$ \\
Motivation & 1,058 &, 367 \\
Emotion & 1,062 &, 366 \\
Social Interaction & 1,274 &, 284 \\
\hline
\end{tabular}

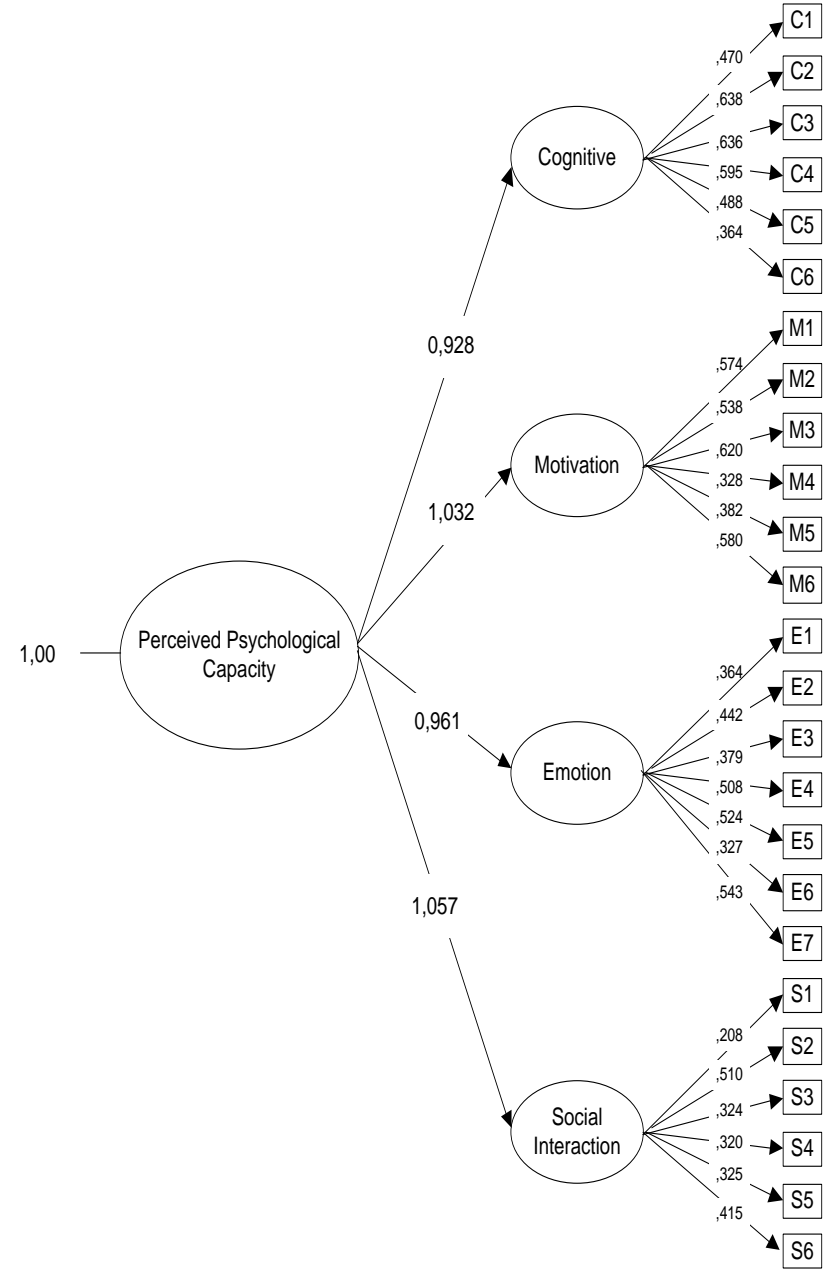

Fig 1. Confirmatory Factor Analysis Result

After elimination of the items that loaded on both factors (cutoff criteria of .35) and considerate the importance content of the item, 25 item questionnaire was derived that formed the initial scale. Model fit was also determined by the root mean square error of approximation (RMSEA). Values of .08 or less indicate a reasonably fitting model relative to the model's degrees of freedom ${ }^{(14)}$. The result showed that this model is acceptable fit (RMSEA $=0,075)$.

\section{Discussion}

Based on the result of study 1 (pilot study), according to evaluation process of a panel of experts, Perceived Psychological Capacity Scale consist of 34 items (from 40 items earlier) which measure employees' psychological capacity based on their perception. These 34 items measure how employees' perception concerning 4 psychological capacities dimensions, i.e. cognitive, motivation, emotion, and social interaction on their selves in productive lifespan period to end of employment (39-56 years old). Through panel discussion with expert judgment, the Perceived Psychological Capacity Scale content is fulfilled.

Based on the result of study 1 and study 2, the results showed that the EFA indicated a clear four-factor structure. We derived 25 items of Psychological Capacity Scale. It consist of 6 items for cognitive function (item 1-6), 
6 items for (work) motivation (item 7-12) , 7 items for emotional aspect ( item 13-19) and 6 items for social interaction ( item 20-25). The EFA indicated support for discriminant validity. This result indicates that Psychological Capacity Scale can measure the decrease of psychological capacity based on employees' perceived perception particularly in service work scope on certain age. This means Perceived Psychological Capacity Scale (that build by cognitive, motivation emotion, and social interaction construct) can give illustration of employees' psychological capacity condition in the productive lifespan.

Based on Study 2, which correlate 4 aspects of psychological capacity (cognitive, motivation, emotions, social interaction) with employees' capacity measurement from capital perspective, referred as Human Capital (consist of Psychological Capital, Intellectual Capital, Emotional Capital dan Social Capital) shows the result that three aspects of Perceived Psychological Capacity Scale correlated significantly with the dimension of Human Capital. The highest correlation is in motivation aspect in Psychological Capacity Scale with Psychological Capital on Human Capital measurement. Only the perceived cognitive aspects that not show correlation with intellectual capital measurement. This can be caused by cognitive dimension factors measured in Psychological Capacity Scale have different Intellectual Capital components than what is measured in Human Capital Components. It was implied that overall our Perceived Psychological Capacity Scale have the good criterion validity.

According to difference classification of age, we found that there are no significant differences in all of psychological capacity dimensions based on age classification. The result stated that only cogntive aspects that vary by age. Therefore, the nature of Psychological Capacity Scale items/questions is to discover decline or downturn happened in a certain age. Thus, cognitive aspect tends to change significantly when age gets higher. As employee becoming older, they will feel decline on cognitive capacity, especially in thinking flexibility and memory. Whereas overall work motivation, emotion, and social interaction do not shows any significant decline. Based on additional data from Focus Group Discussion (FGD), work motivation build from a quite great passion to give the best service, even though phisical energy tend to decline in older employees (50-56 years old), their psychological energy are still manage to motivate work. Emotional capacity and social interaction are also remain maintained until retirement age. Employee perceived emotional capacity and social interaction relatively equal.

From the viewpoint of Human Capital employee capital can be develop, but cognitive capacity can only be maintained in the age 40-56 years old. It is significantly uncorrelated with Intellectual Capital. Human Capital perspective stated that 4 capital/assets components of employee can still be increased with stimulation by structured coaching, education, training, and development through employees' work lifespan. Thus, Psychological Capacity Scale, which measure employee perception regarding the downturn psychological capacity in middle adulthood period, can be considered to determine productive lifespan and retirement age limit. Also, the correlation result with Human Capital measurement shows Human Resource Management can create a system management and Human Resource Coach which can prevent the declining of cognitive function and maintain, even increase work motivation, emotion, and social interaction capacity longer. With these strategic steps, the retirement age limit can be considerate to move to 65 years old as WHO sets as youth limit.

\section{Conclusion}

This study is limited on employees of railways transportation service company, with age classification of 39-56 years old about their psychological capacity. Although validation and reliability studies show that Perceived Psychological Capacity Scale valid and reliable, we cannot generalize the findings of this study for every employee in other jobs and company. Therefore, further research needed to be done to measure employee's perception about Psychological Capacity with other than service line of work. Limitation of this research related to the detailed age classification and differential test on work group types (e.g. operational and non-operational, service and non-service, staff and managerial). Advance research also needed to give more specific and thorough illustration of psychological capacity maximum function to work productivity, so it can be a consideration in determining retirement age.

\section{REFERENCES}

[1] Villosio C, Di Pierro D, Giordanengo A, Pasqua P, Richiardi M. Working conditions of an ageing workforce. Luxembourg: Office for Official Publications of the European Communities.; 2008.

[2] De Cuyper N, De Jong J, De Witte H, Isaksson K, Rigotti T, Schalk R. Literature review of theory and research on the psychological impact of temporary employment: Towards a conceptual model. Int J Manag Rev. 2008;10(1):25-51.

[3] Santrock JW, Santrock JW. Essentials of life-span development. New York: McGraw Hill; 2014.

[4] Elizabeth Hurlock. Psikologi Perkembangan Suatu Pendekatan Sepanjang Rentang Kehidupan. Jakarta: Penerbit Erlangga. Jakarta: Erlangga; 2006.

[5] Irwanto EH, Hadisoepadmo A, Priyani R, Wismanto Y, Fernandes C. Psikologi umum: buku panduan mahasiswa. Jakarta: Prenhallindo; 2002.

[6] Kaplan S, Cortina J, Ruark G, LaPort K, Nicolaides V. The role of organizational leaders in employee emotion management: A theoretical model. Leadersh Q. 2014;25(3):563-80.

[7] Peng K. Responding to emotions in China: Gender differences and the emotion-job outcome relationship. Asia Pacific J Manag. 2017;34(2):443-60

[8] Calhoun JF, Acocella JR. Psychology of Adjustment and Human Relationships. New York: McGraw Hill; 1990.

[9] Hall CS, Lindzey G. Psikologi Kepribadian 1 Teori-Teori Psikodinamik (Klinis). Yogyakarta: Kanisius; 1993

[10] Peterson SJ, Spiker BK. Establishing the positive contributory value of older workers: A positive psychology perspective. Organ Dyn. 2005;34(2):153-67.

[11] Malinowski P, Lim HJ. Mindfulness at work: Positive affect, hope, and optimism mediate the relationship between dispositional mindfulness, work engagement, and well-being. Mindfulness (N Y) 2015;6(6):1250-62.

Blue Eyes Intelligence Engineering

\& Sciences Publication 
[12] Santrock JW. Life Span Development. New York: McGraw-Hill; 2011.

[13] Goodwin LD, Leech NL. The meaning of validity in the new standards for educational and psychological testing: Implications for measurement courses. Meas Eval Couns Dev. 2003;36(3):181-91.

[14] Browne M., Cudeck R. Alternative ways of assessing model fit. Testing structural equation models. Newbury Park, CA: Sage Publications; 1993. 136-162 p.

[15] Hu LT, Bentler PM. Cutoff criteria for fit indexes in covariance structure analysis: Conventional criteria versus new alternatives. Struct Equ Model a Multidiscip J. 1999;6(1):1-55.

[16] Byrne BM. Structural equation modeling with AMOS: Basic concepts, applications, and programming. Mahwah, NJ: Lawrence Erlbaum Associates, Inc.; 2001.

[17] Dziuban CD, Shirkey EC. When is a correlation matrix appropriate for factor analysis? Some decision rules.No Title. Psychol Bull. $1974 ; 81(6): 358$

\section{AUTHORS PROFILE}

My good name is Marina Sulastiana, my current affiliation is with Faculty of Psychology, Universitas Padjadjaran, Jatinangor, West Java. marina.sulastiana@unpad.ac.id. My area of interest is development and validation.

Dhevy Puswiartika, right know I am working with Faculty of Psychology, Universitas Padjadjaran, Jatinangor, West Java. Development and learning is my area of interest.

Rezki Ashriyana Sulistiobudi, my affiliation is with Faculty of Psychology, Universitas Padjadjaran, Jatinangor, West Java. My interests are finding new research and development.

Ernie Tisnawati Sule, affiliated with BUMN Centre of Excellence , Universitas Padjadjaran, Jatinangor, West Java. My interests are in learning and development. 